\title{
Dynamic Programming and the Computation of Econonic Injury Levels for Crop Disease Control
}

\author{
David W. Onstad* \& Rudy Rabbinge \\ Department of Theoretical Production Ecology, Agricultural University, \\ Wageningen, The Netherlands
}

\begin{abstract}
SUMMARY
We explain how dynamic programming can be used to determine the optimal solutions to models for crop disease control. In many cases, these solutions are the sets of dynamic economic injury levels that make management of the diseases more efficient. Three different models of yellow rust and cereal aphids on wheat are solved with dynamic programming to demonstrate its advantages and limitations.
\end{abstract}

\section{INTRODUCTION}

As modern agriculture has developed over the last few decades, efficiency has been replacing maximum production as a major goal in many economic systems. To improve the efficiency of crop protection, Stern et al. (1959) developed the concept of the economic injury level, which focused attention on both the costs and benefits of pest control. In the past, most of the research in this area dealt with insect pest management, but after the development of modern fungicides, interest in economic injury levels for pathogen and disease control increased. Now the need for dynamic economic injury levels has been recognized by workers in a variety of disciplines. These levels vary with time and with changes in the

* Present address: Department of Entomology, Cornell University, New York State Agricultural Experiment Station, Geneva, NY 14456, USA.

Agricultural Systems 0308-521X/85/\$03.30 Elsevier Applied Science Publishers Ltd, England, 1985. Printed in Great Britain 